TREE-RING RESEARCH, Vol. 61(1), 2005, pp. 21-32

\title{
MULTICENTENNIAL RING-WIDTH CHRONOLOGIES OF SCOTS PINE ALONG A NORTH-SOUTH GRADIENT ACROSS FINLAND
}

\author{
SAMULI HELAMA* \\ Department of Geology \\ P.O. Box 64, Gustaf Hällströminkatu 2 \\ FIN-00014 University of Helsinki, Finland \\ MARKUS LINDHOLM, JOUKO MERILÄINEN \\ Saima Centre for Environmental Sciences \\ University of Joensuu \\ P.O. Box 55 \\ FIN-57101 Savonlinna, Finland \\ MAURI TIMONEN \\ Finnish Forest Research Institute \\ Rovaniemi Research Station \\ Box 16, FIN-96301 Rovaniemi, Finland \\ and \\ MATTI ERONEN \\ Department of Geology \\ P.O. Box 64, Gustaf Hällströminkatu 2 \\ FIN-00014 University of Helsinki, Finland
}

\begin{abstract}
Four regional Scots pine ring-width chronologies at the northern forest-limit, and in the northern, middle and southern boreal forest belts in Finland cover the last fourteen centuries. Tree-ring statistics and response functions were examined, and tree-ring width variation was also compared to North Atlantic Oscillation (NAO) and volcanic forcing. The tree-ring statistics show evidence of an ecogeographical gradient along a north-south transect. The three northernmost regional chronologies share a positive response to mid-summer temperature, and all four chronologies show positive and significant correlation to early-summer precipitation. Moreover, a positive and significant relationship to winter NAO was detected in three out of four regional chronologies. NAO also drives the common (inter-regional) growth variability. Years of known cool summers caused by volcanic forcing exhibit exceptionally narrow tree rings in the three northernmost regional chronologies.
\end{abstract}

Keywords: Dendroclimatology, Scots pine, Finland, subfossil, North Atlantic Oscillation, volcanic forcing.

\section{INTRODUCTION}

The study of Scots pine tree rings has a long tradition in Finland. Recent dendroclimatological advances have yielded century and millennium-

*Corresponding Author: samuli.helama@helsinki.fi length regional ring-width chronologies for northern, central and southern Finland. These chronologies result from a long program of sample collection that has produced large numbers of crossdated tree-ring series from natural and historical archives. Dendrochronologically well-developed 
regions form a transect across the country. Some of these chronologies are available in the ITRDB (http://www.ngdc.noaa.gov/paleo/treering.html). Recently, chronology construction in northern Finland culminated in a seven and one-half millennium-long continuous Scots pine ring-width chronology (Eronen et al. 2002).

The present work consists of two parts. Firstly, each regional chronology is described by means of its statistical properties and response functions. Results are shown in the context of a north-south transect that reveals a possible ecogeographical tree-ring gradient from the northern forest-limit region to the southern boreal forest interior. Secondly, radial growth variations are compared to known volcanic events and North Atlantic atmospheric circulation patterns over the last five centuries. This comparison is aimed at producing information on past relationships between environmental conditions and tree growth in Finland on interannual-to-interdecadal timescales. In relation to previous work (e.g. Lindholm et al. 2000), our analysis includes greatly strengthened regional mean time series, a larger number of statistics (to determine the ecogeographical position of each regional dataset along the transect), as well as a comparison of tree rings with internal and external climate forcings. Results derived here can be used as a basis for ecogeographical tree-ring studies on a broader spatial scale, and they contribute to paleoecology as the known volcanic events provide a high-resolution tool for assessing the past response of these regional chronologies to the growing seasons of extreme climatic conditions. The analysis also illuminates the relationship of large-scale atmospheric circulation to tree-ring variability and its spatiotemporal evolution over past centuries.

\section{MATERIAL AND METHODS}

\section{North-South Transect of Tree-Ring Chronologies}

Four regional Scots pine (Pinus sylvestris L.) tree-ring width chronologies are located along a north-south transect of $900 \mathrm{~km}$ (560 miles). The material was collected from the forest-limit in northern Finnish Lapland (415 trees), Pääjärvi (Pyaozero) (94 trees), North Karelia (156 trees)

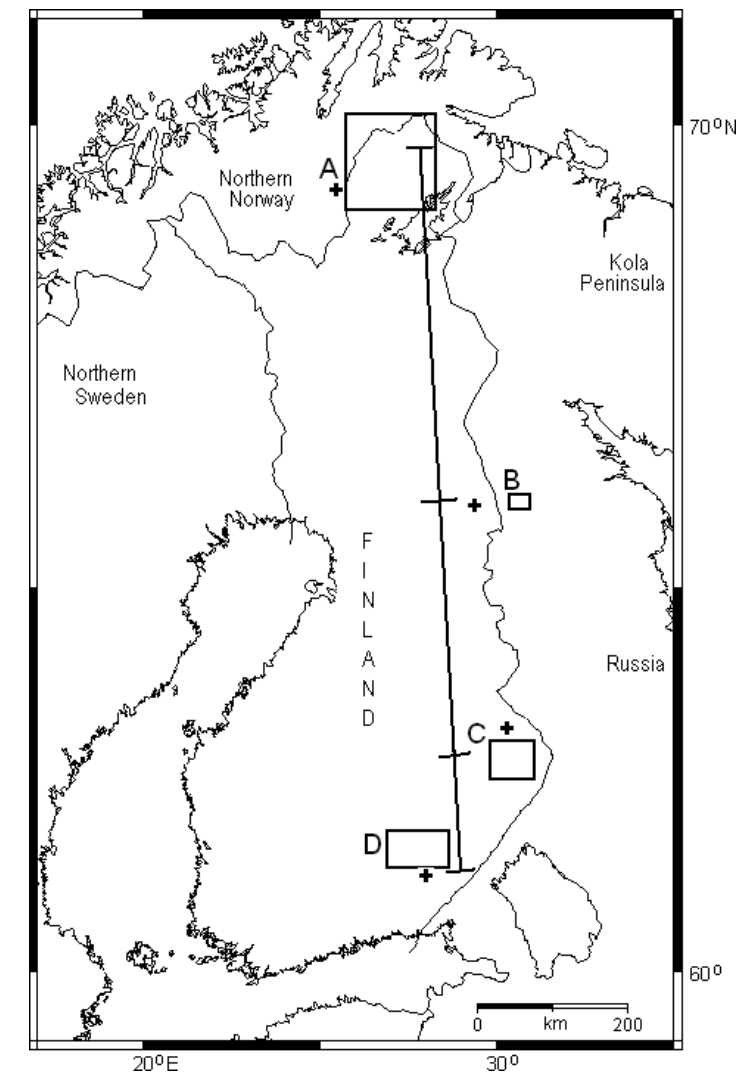

Figure 1. Geographical distribution of the regional chronologies $A, B, C$ and $D$ along the north-south transect. Crosses (+) represent the meteorological stations.

and Lake Saimaa basin district in southeast Finland (563 trees) with abbreviations used hereafter from north to south as $A, B, C$ and $D$ (Figure 1), respectively. Cores from living trees in naturally grown sites, from dead standing trees and buildings were extracted with an increment borer. Samples were also collected from tree trunks in the bottom sediment of small lakes. Disks were cut after lifting the trunks to the surface, after which the trunks were returned into the lake (Eronen et al. 2002). The ring widths were measured to the nearest one-hundredth of a millimeter. Tree-ring series of each tree were estimated by an arithmetic mean of measurements along different radii of each tree. Series of ring widths were then carefully crossdated using several numerical procedures (Aniol 1983; Holmes 1983; Holmes et al. 1986; van Deusen 1990) in addition to visual comparison of the series on a light table. 
The northernmost sampling sites (Region $A$ ) are situated along the forest-limit zone. They represent sites at the worldwide distribution limit of the species (Mirov 1967). Samples were extracted from living trees, dead standing trees and from subfossil wood preserved in the sediment of small lakes. This dataset is a subsample of the multi-millennial ring-width chronology of Eronen et al. (2002). The second set of samples (Region $B$ ), including dead and living trees, comes from the border of the north and middle boreal forest belts (sensu Ahti et al. 1968). It was presented earlier by Lindholm (1996). The third set of samples (Region $C$ ) comes from the border of the middle and south boreal forest belts, whereas the southernmost samples (Region $D$ ) clearly originate from the southern boreal forest belt. An earlier version of the southernmost chronology was briefly discussed by Lindholm et al. (1998-1999); here the chronology is 200 years longer and in a more statistically reliable form, owing to the ongoing advances in dendrochronology in that part of the country. The latter two datasets (Region $C$ and $D$ ) both contain samples from living trees, construction timber and preserved trunks in the sediment of small lakes and peat bogs.

\section{Meteorological Time Series}

Meteorological data come from four weather stations, each located in the vicinity of the dendrochronological study region (Figure 1). Station records (from north to south) of Karasjok, Kuusamo, Lieksa and Lappeenranta all contain instrumental measurements of monthly mean temperature and total monthly precipitation for the last 90 years. Annual mean temperatures at the stations are $-2.0,-0.4,1.9$ and $3.6^{\circ} \mathrm{C}$ from north to south, respectively, and annual precipitation totals, are 343, 576, 597 and 632 millimeters from north to south, respectively. To estimate the relationship between tree-ring width and North Atlantic Oscillation (NAO), monthly indices derived by Hurrell (1995) were used.

\section{Ring-Width Indices}

Individual ring-width series were indexed using a two-step process of Holmes et al. (1986) called double-detrending. A negative exponential curve or a linear regression line with a negative slope or line through the series mean were fitted to the measurement series, and indices were derived from the curve by division. Using the formula of Fritts et al. (1969), a negative exponential curve can be modeled as:

$$
y=a e^{-b x}+k, \quad a>0, \quad b>0,
$$

where $a$ determines the initial height of the curve, $b$ controls its concavity and $k$ is a constant representing the translation of the $x$-axis (tree cambial age). This function is mainly expected to capture the age-size related trend in radial growth. A spline function (Cook and Peters 1981) with a frequency response of two-thirds of the individual series length with 50 percent cutoff (Cook 1985) was fitted to the ratio-based indices of the first detrending, and final indices were derived from the curve by division. This fairly stiff spline function is expected to capture tree-ring variation related to disturbance caused by forest dynamics, i.e. non-climatic factors (Cook 1985). The indices were further prewhitened using Box and Jenkins (1970) methods of autoregressive and moving-average time-series modelling (e.g. Cook 1985; Monserud 1986). The order of the autoregressive-moving-average process was determined using Akaike (1974) information criteria. Prewhitening transforms autocorrelated series into a series of independent observations by extracting residuals from the modeled process.

Chronologies were produced averaging the annual values of indices by arithmetic mean. In order to adjust variance for sample size, each annual value was scaled by an effective number of independent samples available in each year (see Osborne et al. (1997) for details). Residual chronologies were used to examine variations in tree rings on an interannual basis, whereas standard chronologies (without prewhitening) were used to study variations of lower frequencies.

The Expressed Population Signal (EPS) statistic was used to measure chronology confidence. EPS is a function of mean intertree correlation (signal of common growth) and sample size (see Wigley et al. (1984)). For EPS, the level of 0.85 (Wigley et al. 1984) was used as a chronology confidence 


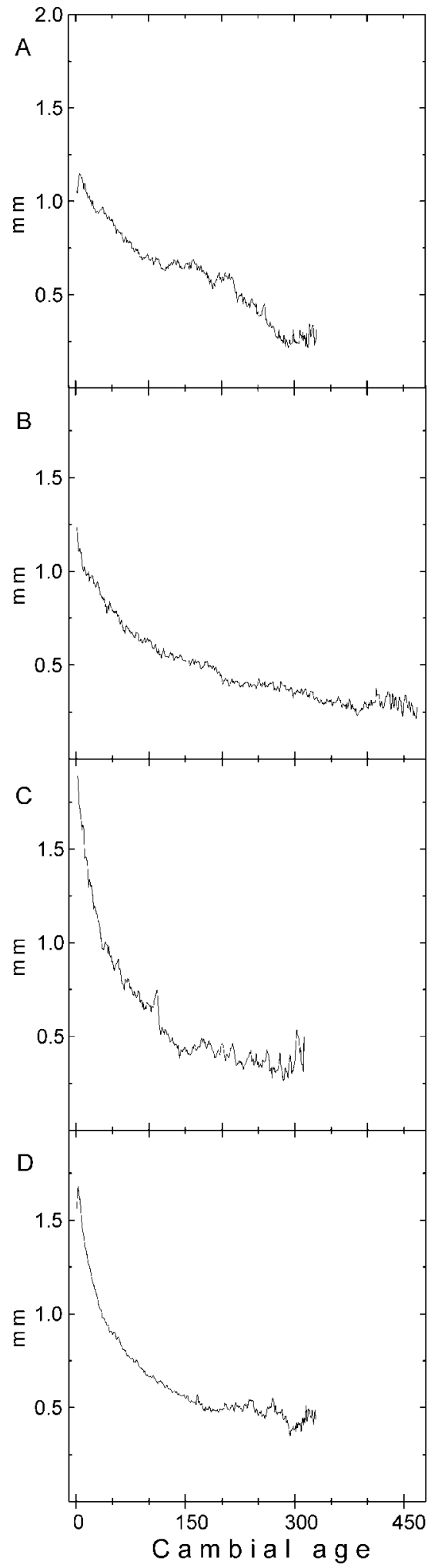

limit. A quantitative analysis here is made only for those parts of the chronologies where EPS is greater than the predetermined level.

\section{RESULTS AND DISCUSSION}

\section{Reliability of Chronologies}

The chronology from Region $A$ remains reliable (according to EPS-statistic) over its entire presented length. The chronology from Region $B$ remains reliable continuously from A.D. 1520 s to present and the chronology from Region $C$ from the 1430 s to present (and occasionally before that) (see Figure 5). The chronology from Region $D$ is reliable from the 580s to present. The EPS-statistic determines the common period (1520-1993), which allows statistically reliable comparison between all four regional chronologies. Hereafter, comparisons between all four chronologies were made using this particular period if not indicated otherwise.

\section{Tree-Ring Statistics}

Individual series of ring widths, measured from pith to bark, are known to contain a trend, associated with age-size dependency in radial growth (Fritts et al. 1969; Cook 1987) (Figure 2). The juvenile stage of growth clearly exhibits a higher level in the two southernmost Regions $(C$ and $D$ ) than in the two northern Regions $A$ and $B$. In addition, narrowing of the ring widths after the juvenile stage of growth is stronger in the south compared to the north, revealed by a greater concavity of the average growth curves in Figure 2. This can be also observed in the change of the region-wide mean value of the constant $b$ (Eqn. 1 ). That is, the mean value of $b$ increases towards the south, indicating an increased concavity (narrowing of the ring widths) in age-size-related growth-trend models of individual measurement

Figure 2. Average growth as a function of cambial age in the Regions $A, B, C$ and $D$. After the juvenile growth maximum, radial growth experiences a more or less exponential decline, with greater concavity of the growth curves in the south than in the north (see also Figure 3). 


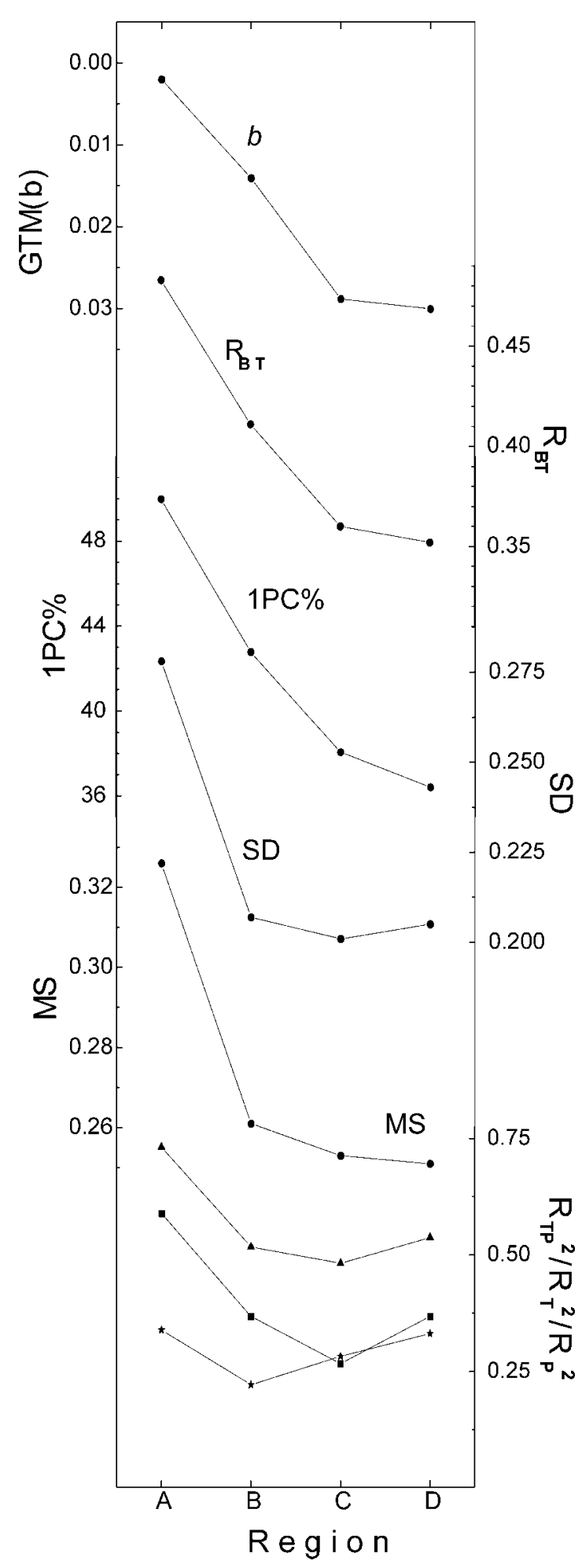

series (see Eqn. 1). According to Mikola (1950), the juvenile maximum of Scots pine radial growth, as well as the concavity of the age-related ringwidth curve, both show a general increase from north to south in natural forests in Finland. Mikola (1950) associated the change in the concavity of the growth trend with an increased growth competition in the same direction. We suggest that the change in the behavior of the age-size related growth trend models can be associated with an ecogeographical change through the transect.

In general, there is a gradual change in most of the computed region-wide ring-width statistics (Figure 3). The common growth signal $\left(\mathrm{R}_{\mathrm{BT}}\right.$ and 1PC\% in Figure 3) decreases through the transect from north to south. The variability (mean sensitivity and standard deviation) shows a similar pattern of reduction southward with greatest change between Regions $A$ and $B$. Increased interannual variability in pine ring widths from the southern parts of Finland to the northern forest-limit was noted already by Hustich (1948) and Mikola (1950). According to Fritts et al. (1965), the common growth signal and series variability are in general supposed to increase from forest interior to the distributional limit of the species. This is partly caused by wider inter-tree spacing (low tree density) near and at the forest-limit. Because of decreased impact of competition, tree growth is more strongly influenced by climate instead of disturbance occurring in the forest interior. This is expected to increase the common growth signal towards the north in the present study.

Chronology variance depends, at least to some degree, on the series intercorrelation within a region (Figure 3). That is, higher correlation between the individual tree-ring series can yield larg-

$\leftarrow$

Figure 3. Variation in chronology statistics from region to region. Comparison includes the mean concavity of the age-related growth trend models by growth trend modelling (GTM; $b$ in Eqn. 1), correlation between the trees $\left(\mathrm{R}_{\mathrm{BT}}\right)$, variance explained by the first principal component (1PC\%), standard deviation (SD) and mean sensitivity (MS). Variance explained by monthly variables of temperature $\left(\mathrm{R}_{\mathrm{T}}{ }^{2}\right)$ is shown as squares, variance explained by precipitation $\left(\mathrm{R}_{\mathrm{P}}{ }^{2}\right)$ as stars, and variance explained by both temperature and precipitation $\left(\mathrm{R}_{\mathrm{TP}}{ }^{2}\right)$ as triangles. 
er variance in the chronology. Series intercorrelation within a region, on the other hand, increases with low growth disturbance and climatic severity. Harsh climate governs pine radial growth over a variety of sites with homogeneity at the northern forest-limit (Lindholm 1996). Moreover, standard deviation of annual mean temperatures is also higher in northern relative to southern Finland (Heino 1994), with an expected influence on treering growth.

\section{Climatic Forcing}

The total chronology variance explained by temperature and/or precipitation variables (using linear regression) shows distinct differences from region to region (Figure 3 ). Climatic factors explain more variance in the ring widths in Region $A$ than in any other regions. This difference is clearest for temperature alone. In the case of precipitation variables, pines from Region $D$ exhibit nearly equal coefficients of determination $\left(\mathrm{R}^{2}\right)$ as pines from Region $A$.

Response functions (by Pearson correlation) using monthly climatic variables (1910-1993) exhibit parallel but also even reverse features among the four regions (Figure 4). It is noteworthy that there is a positive, significant impact of the concurrent July mean temperature on radial growth as a common factor for the three northernmost Regions ( $A$, $B$ and $C$ ). However, in the southernmost Region $D$, pines responded negatively to summer (June) temperatures, whereas total precipitation in May bears a positive, significant response to ring widths in all four regions. Early-summer (May-June) precipitation has a most prominent influence on growth in Region $D$, whereas precipitation in June and July has a negative, significant influence on the tree rings in Regions $B$ and $A$, respectively. Considering the most significant climatic factors affecting the radial growth of pine, response functions from the north (Region $A$ ) and south (Region
$D)$ are in line with works of Lindholm (1996) and Henttonen (1984), respectively. That is, the strong influence of mid-summer temperatures of the concurrent year on ring widths in the north gradually changes into a relatively more dominant influence of early-summer rainfall in the south (Lindholm et al. 2000).

With regard to NAO, there is a gradual shift from late-fall/early-winter to enhanced early-winter impact from north to south (Figure 4), i.e. from Region $A$ to $B$, and from $B$ to $D$. Notably, no significant and negative relationship was found in any of the four chronologies. Relationships between winter-NAO and Scots pine growth in different parts of Finland have been reported previously by D'Arrigo et al. (1993), Cook et al. (1998), Lindholm et al. (2001) and Macias et al. (2004).

\section{Correlations Between Regional Chronologies}

In general, correlations between regional chronologies decrease with increased distance between regions (Figure 5). Correlations between the highfrequency components of ring-width variation decrease more rapidly with increasing distance than the correlations between the low-frequency components of the same data sets. That is, after the long-term variation has been extracted from total variation by Gaussian filters (Figure 5), correlations between these 'low-pass' filtered chronologies are higher with increased distance than correlations between the same chronologies containing more short-term variation (Figure 5). Also, when the chronology of Region $D$ is compared with other regional chronologies, the correlations between the 'low-pass' filtered chronologies always exhibit the highest coefficients. This could, at least partly, result from a greater level of spatial correlation of (spring) rainfall (see response functions) on its low-frequency band (interdecadal) in relation to the high-frequency band (interannual). Alternatively, this can be caused by more intense

Figure 4. Pine radial growth response (correlation) to monthly mean temperatures, precipitation sums and North Atlantic Oscillation (NAO) indices of previous (with a lower-case letter) and concurrent year of growth (with an uppercase). Horizontal dashed line represents the level of significance $(\mathrm{p}<0.05)$ for Pearson correlations, asterisks $(*)$ mark those monthly variables bearing (significant) impact on radial growth in at least two regions. 


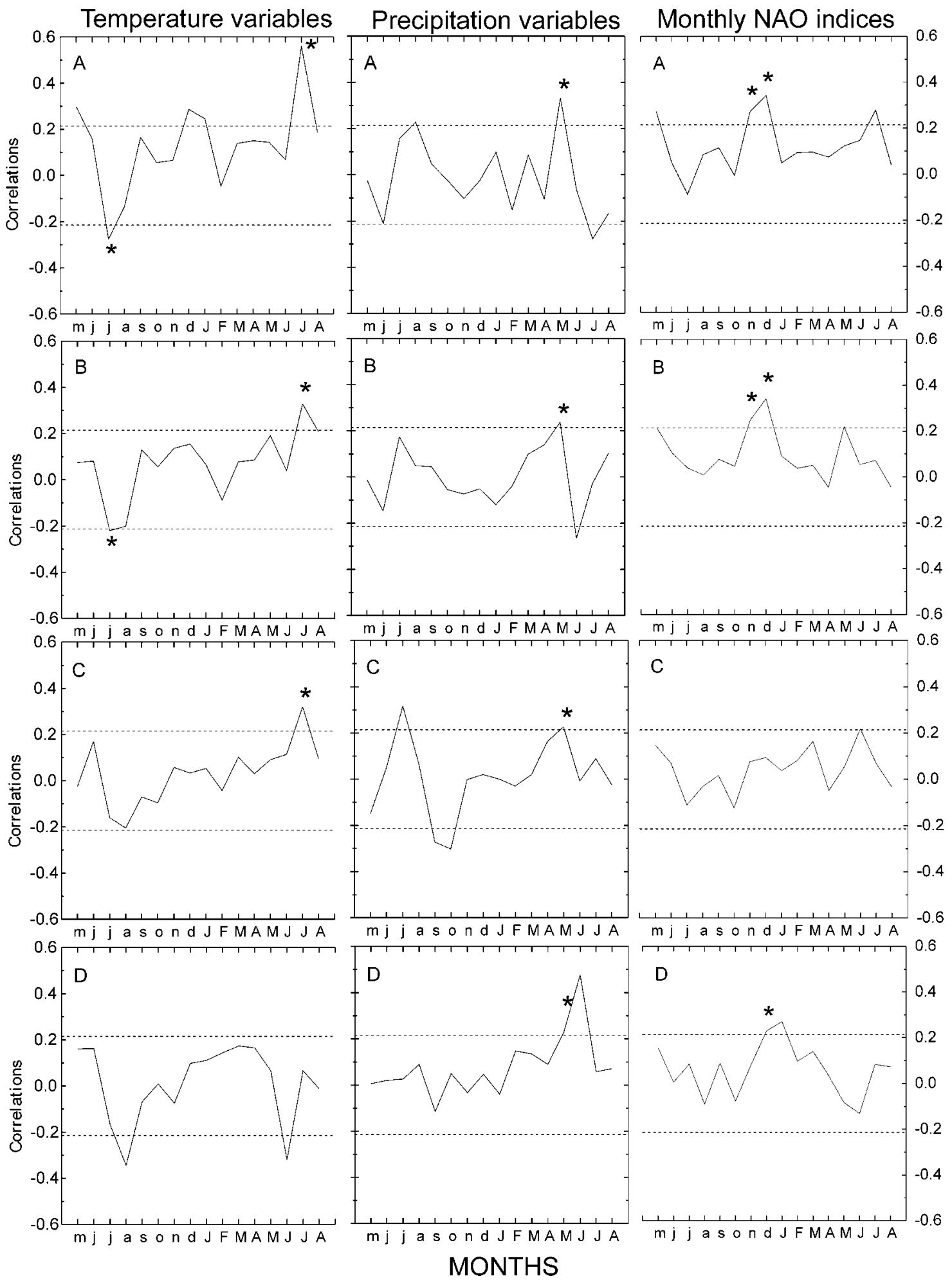


variation in (winter) NAO at decadal and bi-decadal time-scales (see Figure 4). Variations of $\mathrm{NAO}$ on these same time-scales were indeed reported by Rogers (1984) and Cook et al. (1998).

According to Schweingruber (1988), pine ringwidth chronologies in northern Fennoscandia can be synchronized within $800 \mathrm{~km}$. Although a similar pattern of synchronization is supported by the present material (Figure 5), it could be added that in particular it is the high-frequency component of variation that exhibits a drop in inter-correlations after the above-mentioned limit. In addition, correlations between Regions $B$ and $D$ are poorer than could be expected purely from the distance. This is probably caused by the clear difference between growth response to temperature and precipitation variables between northern and southern boreal forest belts (Figure 4). Time-dependent running correlation between Regions $A$ and $D$ (Figure 5) clearly shows that although chronologies from these two regions do share periods of significant (positive) synchronization, these periods are interrupted by sudden drops in correlation.

\section{Extreme Years of Growth and Volcanic Forcing}

There are no extreme years (determined by the level of 97.5 and 2.5 percentile for positive and negative growth, respectively) common to all regions (Figure 6, Table 1). There are likewise no extremely positive years common to three out of four regions. However, years 1826, 1898 and 1930 are common in Regions $A$ and $B, 1648$ in $B$ and $C$, and 1922 in $C$ and $D$. Years of most suppressed growth are 1601, 1696 and 1806; these years represent annual anomalies of negative ring-width indices in Regions $A, B$ and $C$, and as a rule of a thumb growth suppression is severer northward. However, in Region $D$ all these years represent a
Table 1. Ten most extreme years of growth in different chronologies listed in descending order of amplitude. Number of asterisks $(*)$ indicate the number of joint occurrence with other chronologies.

\begin{tabular}{llll}
\hline \multicolumn{4}{c}{ Positive Extreme Years } \\
\hline $\mathrm{A}$ & $\mathrm{B}$ & $\mathrm{C}$ & $\mathrm{D}$ \\
\hline $1826^{*}$ & 1684 & 1915 & 1957 \\
$1930^{*}$ & $1826^{*}$ & 1882 & 1924 \\
1823 & $1648^{*}$ & $1648^{*}$ & 1890 \\
1689 & 1655 & 1954 & 1694 \\
1964 & 1702 & 1752 & 1934 \\
1626 & $1898^{*}$ & 1793 & 1754 \\
1829 & 1634 & 1885 & $1922^{*}$ \\
$1898^{*}$ & 1707 & $1922^{*}$ & 1921 \\
1738 & 1704 & 1947 & 1691 \\
1594 & $1930^{*}$ & 1570 & 1865 \\
& & & \\
\hline A & $\mathrm{B}$ & $\mathrm{C} a \mathrm{C}$ & $\mathrm{D}$ \\
\hline $1601^{* *}$ & $1696^{* *}$ & 1867 & 1992 \\
1837 & $1601^{* *}$ & $1696^{* *}$ & 1940 \\
1680 & $1806^{* *}$ & $1926^{*}$ & 1889 \\
$1806^{* *}$ & 1719 & $1806^{* *}$ & 1845 \\
$1641^{*}$ & $1641^{*}$ & 1931 & $1926 *$ \\
$1709^{*}$ & $1709^{*}$ & $1601^{* *}$ & 1852 \\
1695 & 1961 & 1835 & 1875 \\
1574 & 1672 & 1928 & 1853 \\
1769 & 1549 & 1803 & 1959 \\
$1696^{* *}$ & 1580 & 1790 & 1969 \\
\hline & & &
\end{tabular}

(slightly negative but) close to average value of growth. During the common period (i.e. last five centuries), Region $D$ experienced only a single year of a negative growth anomaly jointly with the Region $C$ in 1926.

Prior to the common period, Regions $A$ and $D$ exhibit common extremely negative growth in A.D. 618 and common extremely positive growth in 1405 and 1433. Interestingly, in 1495 pine growth was extremely suppressed in Region $A$ and ameliorated in Region $D$.

Figure 5. Variation of four regional chronologies $A, B, C$ and $D$, smoothed with a 20-year Gaussian filter, with corresponding sample size (SS) as grey area. Moving 30-year window correlation between chronologies from Regions $A$ and $D\left(\mathrm{R}_{\mathrm{A}: \mathrm{D}}\right)$ is shown underneath the regional chronologies with two horizontal lines representing the level of significance $(\mathrm{p}<0.01)$ for correlation. In the lowermost part, correlations (R) between the regional chronologies are separately shown as a function of geographical distance, for residual (filled squares) and standard chronologies (open squares), as well as for 10-year (open circles) and 20-year (filled circles) Gaussian 'low-pass' filtered chronologies. 


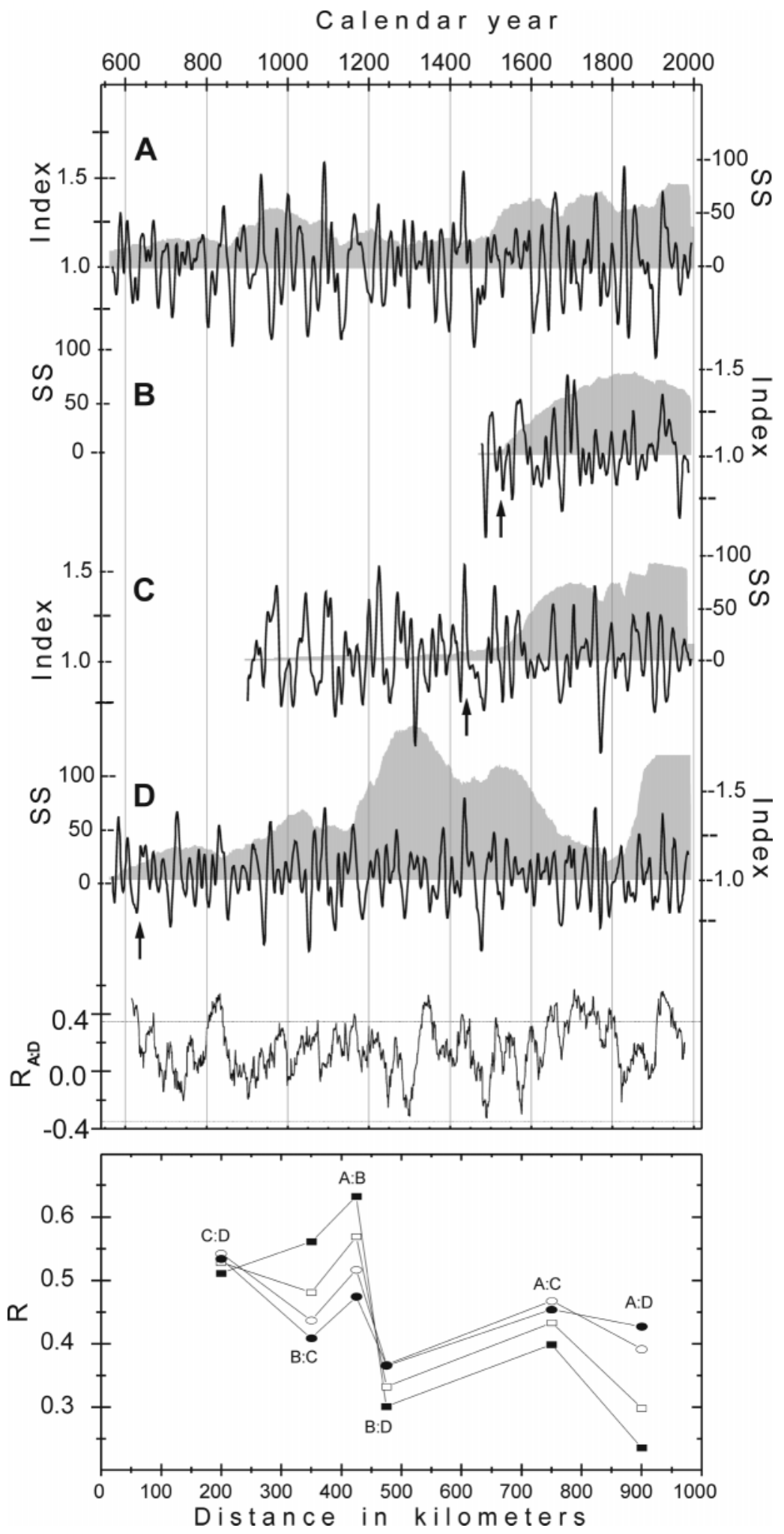




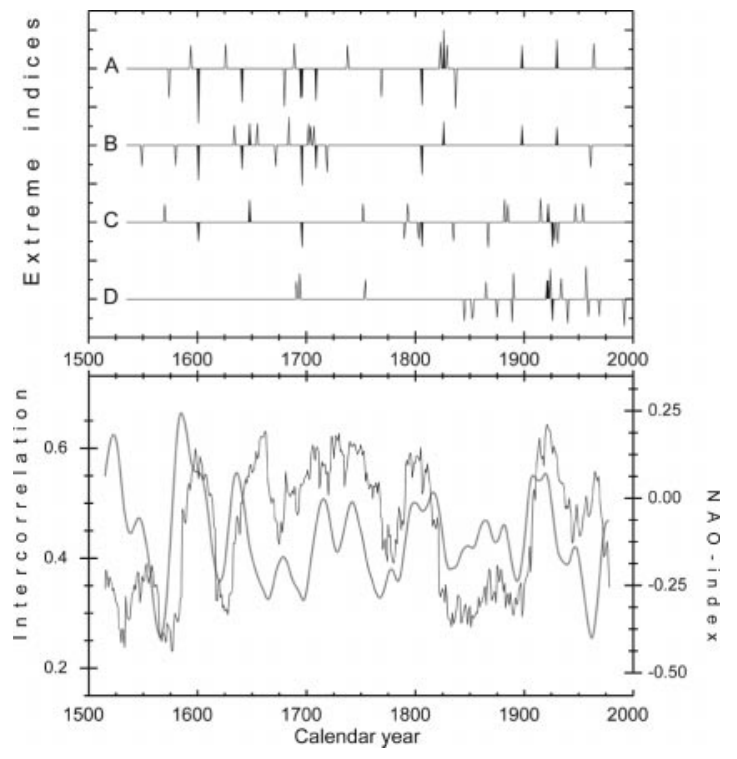

Figure 6. Comparison between most extreme years of growth in each regional chronology (upper panel). Length of each peak shows intensity (strength) of the positive or negative event, and filled peaks show extreme years in at least two regions. Positive years of joint occurrence are 1648, 1826, 1898, 1922 and 1930, whereas corresponding negative years are 1601, 1641, 1696, 1709, 1806 and 1926. In the lower panel, mean correlation between all regional chronologies using a moving 30 -year window (thin line), along with North Atlantic Oscillation (NAO) indices (Cook et al. 2002) filtered by a 30-year cubic spline function (thick line)

Several of the negative extreme years of growth (Figure 6, Table 1) could be associated with known volcanic eruptions, as shown by Gervais and MacDonald (2001) using the summer temperature sensitive Scots pine ring widths from the Kola Peninsula (see Figure 1). The following years from Table 1 also coincide with eruptions (in parenthesis) reported by Gervais and MacDonald (2001): 1601 (Huaynaputina 1600), 1641 (Komaga-Take 1640 and Parker 1641), 1680 (Tongkoko 1680), 1709 (Fuji 1707) and 1837 (Cosiguina 1835). Details of eruptions are compiled by Simkin et al. (1981) and Briffa et al. (1998). The year 1580, listed in Table 1, coincides with the Billy Mitchell eruption in the same year (see discussion in Briffa et al. 1998). In contrast, the negative extreme year 1806 cannot be associated with any single volcanic event known to exert hemispheric influence (see Simkin et al. 1981).
All the years of minimum growth index discussed above in connection with volcanic events occurred in Regions $A, B$ or $C$, and none of them in Region $D$. That is, lowered summer temperatures, forced by volcanic activity (e.g. Kelly and Sear 1984; Bradley 1988) suppressed the pine growth in the regions of northern and middle boreal forest belts (Regions $A, B$ and $C$ ), but not in the south (Region $D$ ), where the summer temperatures of the concurrent year do not have such an impact on pine growth (see Figure 4). However, one can find 1992 as the first in the list of the most extreme negative growth indices in Region $D$ (Table 1). Even this year could be associated with the recent eruption of Pinatubo during the preceding year, and it was also recorded as the driest earlysummer (May-June) at the Lappeenranta weather station (in the vicinity of Region $D$ ) during the calibration period used here.

\section{North Atlantic Oscillation}

After the reconstruction of the winter NAO-index (Cook et al. 2002) and time-dependent common growth signal (mean correlation between all four regional chronologies) for the last five centuries (Figure 6), it seems evident that positive phases of NAO drive common radial growth of pine across Finland. That is, long-term positive phases of NAO coincide with spells of increased common growth signal, and vice versa. This joint occurrence is supported by correlations between ring widths and winter NAO shown above (Figure 4), as well as by the observation of Macias et al. (2004) who found that the intervals of positive NAO particularly impact pine radial growth in Northern Fennoscandia.

\section{CONCLUSIONS}

Four regional ring-width chronologies of Scots pine from Finland were presented. Sampled regions were situated at the northern forest-limit region, and in the northern, middle and southern boreal forest zones. Comparison of tree-ring statistics between the regions showed evidence of a clear ecogeographical gradient through the transect. There was a gradual decline of the common growth signal from north to south, along with in- 
dependent indication of increasing growth competition (i.e. increased concavity in age-size related growth models) in the same direction. When growth trend modeling of Fritts et al. (1969) was used along with a previously defined relationship between inter-tree competition and concavity of pine growth trends (Mikola 1950), the growthtrend modeling was shown to provide a quantitative measure of region-wide competition experienced by pines. Ring-width variance exhibited a distinct drop in mean sensitivity and standard deviation from the forest-limit southward to the other three regions. This change corresponded to a similar drop in the variance explained $\left(\mathrm{R}^{2}\right)$ by the meteorological data (temperature and precipitation). However, based on response functions, the three northernmost regions (forest-limit, northern and middle boreal forests) showed a common (positive and significant) impact of mid-summer (July) temperatures on radial growth, whereas a similar effect of temperature was absent in the southernmost region where early-summer (May-June) precipitation contributed the greatest effect on ring widths. Concurrent May precipitation had a positive, significant impact on tree rings in all four regions.

Correlations between chronologies from neighboring regions were highest in the high-frequency band of ring-width variations, whereas chronologies farther apart correlated better in the low-frequency band of growth variability. This may imply that long-term climatic variations were more synchronized over distances in relation to the shortterm variations, or, that common variation on decadal and bi-decadal time-scales is contributed by NAO, known to operate at similar frequencies.

Narrow rings were associated with volcanic events over the three northernmost regions. The absence of volcanic signatures in the southernmost region is caused by lack of growth response to summer temperatures. Volcanic effects on tree rings were found to be generally severest in the northernmost regions, where the growth response to summer temperatures was also strongest. As the comparison was made over the last five centuries, the latter response suggests that relative response of pine growth to summer temperatures in all four regions has remained somewhat unchanged over the same period of time.

\section{ACKNOWLEDGMENTS}

The careful measurement of ring widths by several assistants at the Saima Centre for Environmental Sciences, Savonlinna, and at Finnish Forest Research Institute, Rovaniemi Forest Research Station is acknowledged. The corresponding author thanks Marc Macias for inspiring communications on various aspects of the work. We are also grateful to the three anonymous referees for comments on the earlier version of the manuscript that considerably improved the final presentation.

\section{REFERENCES CITED}

Ahti, T., L. Hämet-Ahti, and J. Jalas

1968 Vegetation zones and their sections in northwestern Europe. Annales Botanici Fennici 3:169-211.

Akaike, $\mathrm{H}$.

1974 A new look at the statistical model identification. IEEE Transactions on Automatic Control AC-19: 716-723.

Aniol, R. W.

1983 Tree-ring analysis using CATRAS. Dendrochronologia $1: 45-53$.

Box, G. E. P., and G. M. Jenkins

1970 Time Series Analysis: Forecasting and Control. Holden-Day, San Francisco; 553 pp.

Bradley, R. S.

1988 The explosive volcanic eruption signal in northern hemisphere continental temperature records. Climatic Change 12:221-243.

Briffa, K. R., P. D., Jones, F. H., Schweingruber, and T. J. Osborn

1998 Influence of volcanic eruptions on Northern Hemisphere over the past 600 years. Nature 393:450-455.

Cook, E. R.

1985 A Time Series Analysis Approach to Tree-ring Standardization. Ph.D. dissertation, University of Arizona, Tucson; $171 \mathrm{pp}$.

Cook, E. R.

1987 The decomposition of tree-ring series for environmental studies. Tree-Ring Bulletin 47:37-59.

Cook, E. R., R. D. D'Arrigo, and K. R. Briffa

1998 A reconstruction of the North Atlantic Oscillation using tree-ring chronologies from North America and Europe. The Holocene 8:9-17.

Cook, E. R., R. D. D'Arrigo, and M. E. Mann

2002 A well-verified, multiproxy reconstruction of the winter North Atlantic Oscillation Index since A.D 1400. Journal of Climate 15:1754-1764.

Cook, E. R., and K. Peters

1981 The smoothing spline: A new approach to standardizing forest interior tree-ring width series for dendroclimatic studies. Tree-Ring Bulletin 41:45-53. 
D’Arrigo, R. D., E. R. Cook, G. C. Jacoby, and K. R. Briffa 1993 NAO and sea surface temperature signals in tree-ring records from the North Atlantic sector. Quaternary Science Reviews 12:431-440.

Eronen, M., P. Zetterberg, K. R. Briffa, M. Lindholm, J. Meriläinen, and M. Timonen

2002 The supra-long Scots pine tree-ring record for northern Finnish Lapland-Part 1: chronology construction and initial inferences. The Holocene 12:673680.

Fritts, H. C., J. E. Mosimann, and C. P. Bottorff

1969 A revised computer program for standardizing treering series. Tree-Ring Bulletin 29:15-20.

Fritts, H. C., D. G. Smith, C. A. J. W. Cardis, and C. A. Budelsky

1965 Tree-ring characteristics along a vegetation gradient in Northern Arizona. Ecology 46:393-401.

Gervais, B. R, and G. M. MacDonald

2001 Tree-ring and summer-temperature response to volcanic aerosol forcing at the northern tree-line, Kola Peninsula, Russia. The Holocene 11:499-505.

Heino, R.

1994 Climate in Finland during the period of meteorological observations. Finnish Meteorological Institute Contributions 12:1-209.

Henttonen, $\mathrm{H}$

1984 The dependence of annual ring indices on some climatic factors. Acta Forestalia Fennica 186:1-38.

Holmes, R. L.

1983 Computer-assisted quality control in tree-ring dating and measurement. Tree-Ring Bulletin 43:69-75.

Holmes, R. L., R. K. Adams, and H. C. Fritts

1986 Tree-Ring Chronologies of Western North America: California, Eastern Oregon and North Great Basin with Procedures Used in the Chronology Development Work Including Users Manuals for Computer Programs COFECHA and ARSTAN. Chronology Series VI. Laboratory of Tree-Ring Research, University of Arizona, Tucson.

Hurrell, J. W.

1995 Decadal trends in the North Atlantic Oscillation and relationships to regional temperature and precipitation. Science 269:676-679.

Hustich, I.

1948 Scotch pine in northernmost Finland and its dependence on the climate in the last decades. Acta Botanica Fennica 42:1-75.

Kelly, P. M., and C. B. Sear

1984 Climatic impact of explosive volcanic eruptions. $\mathrm{Na}$ ture 311:740-743

Lindholm, M.

1996 Reconstruction of Past Climate from Ring-width Chronologies of Scots Pine (Pinus sylvestris L.) at the Northern Forest Limit in Fennoscandia. Ph.D. dissertation, University of Joensuu, Publications in Sciences 40; 169 pp.

Lindholm, M., Ó. Eggertsson, N. Lovelius, O. Raspopov, O. Shumilov, and A. Läänelaid

2001 Growth indices of North European Scots pine record the seasonal North Atlantic Oscillation. Boreal Environmental Research 6:275-284.

Lindholm, M., H. Lehtonen, T. Kolström, J. Meriläinen, M. Eronen, and M. Timonen

2000 Climatic signals extracted from ring-width chronologies of Scots pine from the Northern, Middle and Southern parts of the boreal forest belt in Finland. Silva Fennica 34:317-329.

Lindholm, M, J. Meriläinen, and M. Eronen

1998 A 1250-year ring-width chronology of Scots pine for south-eastern Finland, in the southern part of the boreal 1999 forest belt. Dendrochronologia 16-17:183190.

Macias, M., M. Timonen, A. Kirchhefer, M. Lindholm, M. Eronen, and E. Gutierrez

2004 Growth variability of Scots pine along a West-East gradient across Northern Fennoscandia: a dendroclimatic approach. Arctic, Antarctic and Alpine Research 36:565-574.

Mikola, P.

1950 Puiden kasvun vaihteluista ja niiden merkityksestä kasvututkimuksessa. Summary: On the variations in tree growth and their significance to growth studies. Communicationes Instuti Forestatis Fenniae 38:1131.

Mirov, N. T.

1967 The Genus Pinus. Ronald Press, New York; pp. 602.

Monserud, R. A.

1986 Time-series analyses of tree-ring chronologies. Forest Science 32:349-372.

Osborn, T. J., K. R. Briffa, K. R., and P. D. Jones

1997 Adjusting variance for sample-size in tree-ring chronologies and other regional mean timeseries. Dendrochronologia 15:89-99.

Rogers, J.C.

1984 The association between the North Atlantic Oscillation and the Southern Oscillation in the Northern Hemisphere. Monthly Weather Review 112:1999_ 2015 .

Schweingruber, F. H.

1988 Tree Rings. Basics and Applications of Dendrochronology. Kluwer Academic Publishers, Dordrecht, Holland; $276 \mathrm{pp}$.

Simkin, T. L., S. L. McClelland, D. Bridge, C. Newhall, and

J. H. Latter

1981 Volcanoes of the World. Hutchinson Ross, Stroudsburg, Pennsylvania; $232 \mathrm{pp}$.

van Deusen, P. C.

1990 Popular formulations for modeling tree rings from climate: a unifying approach. Journal of Environmental Quality 20:823-827.

Wigley, T. M. L., K. R. Briffa, and P. D. Jones

1984 On the average value of correlated time series, with applications in dendroclimatology and hydrometeorology. Journal of Climatology and Applied Meteorology 23:201-213.

Received 13 November 2002; accepted 14 February 2005. 